\title{
Comparison of ITER Performance Predicted by Semi-Empirical and Theory-Based Transport Models
}

\author{
V. Mukhovatov 1), Y. Shimomura 1), A. Polevoi 1), M. Shimada 1), M. Sugihara 1), \\ G. Bateman 2), J.G. Cordey 3), O. Kardaun 4), G. Pereverzev 4), I. Voitsekhovich 5), \\ J. Weiland 6), O. Zolotukhin 7), A. Chudnovskiy 8), A.H. Kritz 2), A. Kukushkin 7), \\ T. Onjun 2), A. Pankin 2), F.W. Perkins 9)
}

1) ITER International Team, ITER Naka Joint Work Site, Naka-machi, Naka-gun, Ibaraki-ken 311-0193 Japan

2) Lehigh University, Bethlehem, PA 18015, USA

3) EURATOM-UKAEA Fusion Association, Culham Science Centre, Abingdon, UK

4) Association Euratom-IPP, MPI für Plasmaphysik, 2 Boltzmannstrasse, Garching, Germany

5) Equipe Turbulence Plasma, University of Provence, Marseilles, France

6) Chalmers University of Technology and EURATOM-NFR Association, Göteborg, Sweden

7) ITER International Team, ITER Garching Joint Work Site, Garching, Germany

8) Nuclear Fusion Institute, Russian Research Center "Kurchatov Institute", Moscow, Russia

9) General Atomics 13-312, PO Box 85608, San Diego, CA 92186 USA

e-mail contact of main author: mukhovv@itergps.naka.jaeri.go.jp

\begin{abstract}
The values of $\mathrm{Q}=$ (fusion power)/(auxiliary heating power) predicted for ITER by three different methods, i.e., transport model based on empirical confinement scaling, dimensionless scaling technique, and theory-based transport models are compared. The energy confinement time given by the ITERH-98(y,2) scaling for an inductive scenario with plasma current of $15 \mathrm{MA}$ and plasma density $15 \%$ below the Greenwald value is $3.6 \mathrm{~s}$ with one technical standard deviation of $\pm 14 \%$. These data are translated into a $\mathrm{Q}$ interval of [7 - 13] at the auxiliary heating power $\mathrm{P}_{\mathrm{aux}}=40 \mathrm{MW}$ and [7 -28] at the minimum heating power satisfying a good confinement ELMy H-mode. Predictions of dimensionless scalings and theory-based transport models such as Weiland, MMM and IFS/PPPL overlap with the empirical scaling predictions within the margins of uncertainty.
\end{abstract}

\section{Introduction}

Predictions of the plasma performance in reactor scale devices are based largely on empirical global confinement scalings while two other possible approaches, i.e. the dimensionless scaling analysis and application of theory-based transport models are used for comparison, as discussed in connection with the ITER-98 design in Ref. [1]. In this paper we compare the performance of inductively driven plasmas predicted by the three approaches for ITER-FEAT taking into account recent progress in these areas.

\section{Empirical Scaling Approach}

A recent analysis of the enlarged global confinement database (ITERH.DB3) has confirmed the practical reliability of the ITER reference scaling for the thermal energy confinement [1], $\tau_{\mathrm{E}, \mathrm{H} 98(\mathrm{y}, 2)}=0.0562 \mathrm{I}^{0.93} \mathrm{~B}^{0.15} \overline{\mathrm{n}}_{19}^{0.41} \mathrm{P}^{-0.69} \mathrm{R}^{1.97} \kappa_{\mathrm{a}}^{0.78} \varepsilon^{0.58} \mathrm{M}^{0.19}$,

and one technical standard deviation was reduced from \pm 18 to $\pm 14 \%$ leading to a $95 \% \log$ nonlinear interval estimate of $\pm 28 \%$ [2]. The scaling (1) satisfies the Kadomtsev constraint and is expressed in non-dimensional variables as $B \tau_{\mathrm{E}, \mathrm{H} 98(\mathrm{y}, 2)} \propto\left(\rho^{*}\right)^{-2.7} \beta^{-0.9}\left(v^{*}\right)^{-0.01} \mathrm{q}^{-3}$, where $\rho^{*}=\rho_{\mathrm{i}} / \mathrm{a}$, $\rho_{\mathrm{i}}$ is the toroidal ion Larmor radius, $\beta$ is the normalised plasma pressure and $\nu^{*}$ is the normalised collisionality [1]. The point prediction for the thermal energy confinement time in ITER is $\tau_{\mathrm{E}}=3.6 \mathrm{~s}$ at the following reference parameters: plasma current $\mathrm{I}=15 \mathrm{MA}$, toroidal magnetic field $B=5.3 \mathrm{~T}$, electron density (in $\left.10^{19} \mathrm{~m}^{-3}\right) \overline{\mathrm{n}}_{19}=10.1=0.85 \mathrm{n}_{\mathrm{G}}\left(\mathrm{n}_{\mathrm{G}}=\mathrm{I} /\left(\pi \mathrm{a}^{2}\right)\right.$ is the Greenwald density), net heating power $\mathrm{P}=87 \mathrm{MW}$, major plasma radius $\mathrm{R}=6.2 \mathrm{~m}, \kappa_{\mathrm{a}}$ $\equiv \mathrm{V} /\left(2 \pi^{2} \mathrm{Ra}^{2}\right)=1.7$ with $\mathrm{V}$ being the plasma volume, $\varepsilon \equiv \mathrm{a} / \mathrm{R}=0.32$ and average hydrogenic atomic mass $\mathrm{M}=2.5$ [3]. Fig. 1 shows results obtained with $1.5 \mathrm{D}$ transport code ASTRA [4] using the scaling (1) for normalisation of the ion and electron thermal diffusivities. The fusion power $\mathrm{P}_{\text {fus }}$ and $\mathrm{Q}=\mathrm{P}_{\text {fus }} / \mathrm{P}_{\mathrm{aux}}\left(\mathrm{P}_{\mathrm{aux}}\right.$ is the auxiliary heating power) are plotted versus the 
confinement enhancement factor $\mathrm{H}_{\mathrm{H} 98(\mathrm{y}, 2)}=\tau_{\mathrm{E}} / \boldsymbol{\tau}_{\mathrm{E}, \mathrm{H} 98(\mathrm{y}, 2)}$ for the ITER inductive operating regime with the above reference parameters. The data shown satisfy the condition

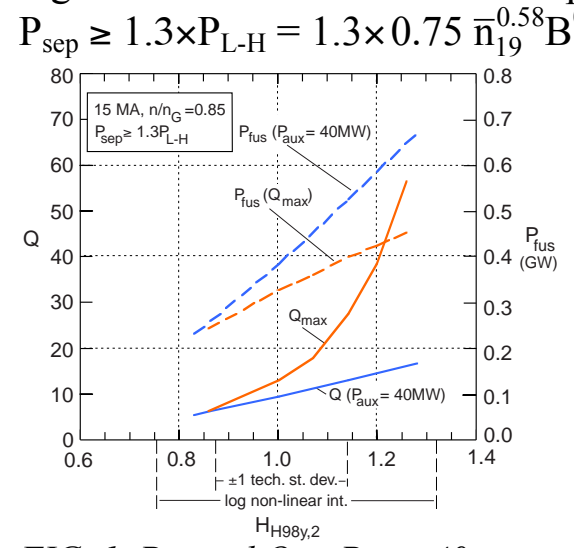

FIG. 1. $P_{\text {fus }}$ and $Q$ at $P_{\text {aux }}=40$ $M W$, and $Q_{\max }$ at $P_{\text {sep }}=1.3 x P_{L-H}$ versus $H_{H 98(y, 2)}$ predicted by ASTRA code.

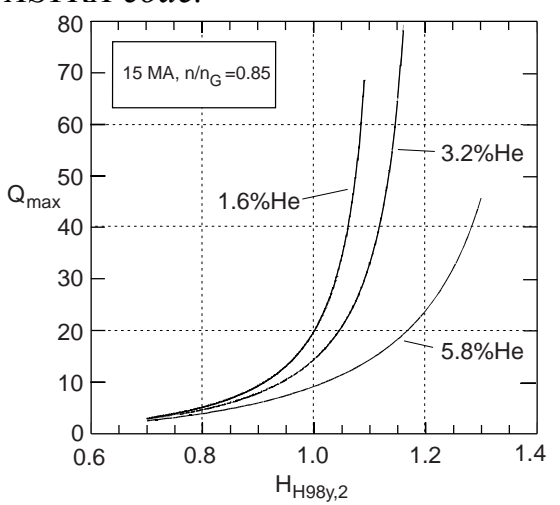

FIG. 2. $Q_{\max }$ versus $H_{H 98(y, 2)}$ at different He content predicted by 1/2D ITINT1.SAS code [2].
${ }^{82} \mathrm{Ra}^{0.81} \mathrm{M}^{-1}\left(\mathrm{MW}, 10^{19} \mathrm{~m}^{-3}, \mathrm{~T}, \mathrm{~m}, \mathrm{amu}\right)$
where $\mathrm{P}_{\text {sep }}$ is the power flow through the separatrix and $\mathrm{P}_{\mathrm{L}-\mathrm{H}}$ is the power threshold for the $\mathrm{L}$ to $\mathrm{H}$ mode transition [5]. A $30 \%$ margin in $\mathrm{P}_{\text {sep }}$ is assumed to be required for obtaining a good confinement ELMy H-mode. While $2 \%$ of Be and $1.2 \%$ of $\mathrm{C}$ ions are assumed to be present in the plasma, the He content is calculated selfconsistently assuming $\tau_{\mathrm{He}}{ }^{*} / \tau_{\mathrm{E}}=$ 5 where $\tau_{\mathrm{He}}{ }^{*}=\tau_{\mathrm{He}} /\left(1-\mathrm{R}_{\mathrm{He}}\right), \tau_{\mathrm{He}}$ is the intrinsic particle confinement time for He nuclei, and $\mathrm{R}_{\mathrm{He}}$ is the effective $\mathrm{He}$ recycling coefficient. At $\mathrm{P}_{\mathrm{aux}}=40 \mathrm{MW}, \mathrm{Q}$ increases with $\mathrm{H}_{\mathrm{H} 98(\mathrm{y}, 2)}$ as $\mathrm{H}_{\mathrm{H} 98(\mathrm{y}, 2)}^{\xi_{\mathrm{H}}}$ with $\xi_{\mathrm{H}} \approx 3$, and the minimum value of $\mathrm{H}_{\mathrm{H} 98(\mathrm{y}, 2)}$ satisfying Eq. (2) is $\approx 0.83$ giving $\mathrm{Q} \approx 5.8$. Because of the negative dependence of $\tau_{\mathrm{E}}$ on the net heating power, $\mathrm{P}$

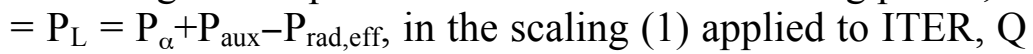
increases with reducing $P_{\text {aux }}$, and the maximum $Q$ is achieved at the lowest $\mathrm{P}_{\text {aux }}$ compatible with Eq. (2), i.e., at $\mathrm{P}$ $=1.3 \mathrm{P}_{\mathrm{L}-\mathrm{H}}$. Here, $\mathrm{P}_{\alpha}$ is the $\alpha$-particle heating power and $\mathrm{P}_{\text {rad,eff }}$ is the effective radiation power loss from the plasma core. $\mathrm{Q}_{\max }$ is a stronger function of $\mathrm{H}_{\mathrm{H} 98(\mathrm{y}, 2)}$ (compared to $\mathrm{Q}$ at $\mathrm{P}_{\mathrm{aux}}=40 \mathrm{MW}$ ) with the exponent $\xi_{\mathrm{H}}$ of about 5 in the vicinity of $\mathrm{H}_{\mathrm{H} 98(\mathrm{y}, 2)}=1$. The interval $[0.87,1.15]$ of $\mathrm{H}_{\mathrm{H} 98(\mathrm{y}, 2)}$ associated with one standard deviation, and the log nonlinear interval $[0.76,1.32]$ translate into $\mathrm{Q}_{\max }$ intervals of $[7$, $28]$ and $[3.5,>80]$, and Q intervals at $P_{a u x} \geq 40 \mathrm{MW}$ of $[7$, $13]$ and $[3.5,18]$, respectively. The sensitivity of $Q$ to other parameters of interest expressed in terms of the exponent $\xi_{\mathrm{y}}$ in the relation $\mathrm{Q} \propto \mathrm{Y}^{\xi_{\mathrm{y}}}(\mathrm{Y}$ denotes parameters $\mathrm{I}, \mathrm{n}, \ldots)$ in the vicinity of the reference operating point is as follows:

$\xi_{\mathrm{I}} \approx 3.4$ for the plasma current at $\mathrm{B}=$ const and $<\mathrm{n}_{\mathrm{e}}>/ \mathrm{n}_{\mathrm{G}}=$ const; $\xi_{\mathrm{n}} \approx 1.6$ for the plasma density at $\mathrm{I}=$ const; and $\xi_{\mathrm{DT}} \approx 2.2\left(\xi_{\mathrm{DT}} \approx 6\right.$ at $\mathrm{P}_{\text {tot }}=\mathrm{P}_{\alpha}+\mathrm{P}_{\mathrm{aux}}=$ const $)$ for the DT ion fraction $\mathrm{f}_{\mathrm{DT}}$ varying with $\tau_{\mathrm{He}} * / \tau_{\mathrm{E}}$ ratio. The $\log$ non-linear interval for $\mathrm{H}_{\mathrm{H} 98(\mathrm{y}, 2)}$ is assumed to cover uncertainties in the ITER performance predictions with the limitations of the power law form of the scaling (1) and with effects of parameters not included in this scaling explicitly, such as the density peaking factor $<\mathrm{n}_{\mathrm{e}}>/ \mathrm{n}_{\text {ped }}$ ( $\mathrm{n}_{\text {ped }}$ is the density at the top of the edge pedestal), closeness to the density limit characterised by the ratio $<\mathrm{n}_{\mathrm{e}}>/ \mathrm{n}_{\mathrm{G}}$, and the plasma triangularity $\delta$. Correction to the scaling (1) i.e. an ancillary scaling of $\mathrm{H}_{\mathrm{H} 98(\mathrm{y}, 2)}$ factor, based on JET only data was suggested in [6] and for the ITERH.DB3v10 database in [2]. For ITER with $\delta=0.5$ and $\left\langle\mathrm{n}_{\mathrm{e}}>/ \mathrm{n}_{\mathrm{G}}=0.85\right.$, this correction gives $\mathrm{H}_{\mathrm{H} 98(\mathrm{y}, 2)}=1.03$ at a moderately peaked density with $\mathrm{n}_{\text {ped }} /<\mathrm{n}>=0.71$ as observed in present day experiments [7] and can be expected in ITER at a proper combination of gas puffing and pellet fuelling [8]. The most unfavourable value here, $\mathrm{H}_{\mathrm{H} 98(\mathrm{y}, 2)}=0.82$, is predicted for ITER plasma with $\mathrm{n}_{\text {ped }} /<\mathrm{n}>=1$, which is slightly outside one technical standard deviation but well inside the log non-linear interval. The offset non-linear two-term scaling suggested in [9] and the analysis in [2] predict relatively low $\tau_{\mathrm{E}}\left(\mathrm{H}_{\mathrm{H} 98(\mathrm{y}, 2)} \approx 0.8\right)$ while the two-term scalings in [10], e.g., the thermal conduction model and the MHD model, predict $\mathrm{H}_{\mathrm{H} 98(\mathrm{y}, 2)}$ very close to 1 although with strongly different relative contributions from the core and pedestal terms.

Above data correspond to moderately conservative assumptions used in the ITER project documentation [3]. Recently, a possibility of reducing the ratio of $\tau_{\mathrm{He}}{ }^{*} / \tau_{\mathrm{E}}$ has been suggested in B2/Eirene code simulations as a result of account of the He elastic collisions [11]. Experimental verification is worthwhile. Fig. 2 illustrates the importance of reducing He contents for maximising $\mathrm{Q}$. One can see that reduction of $\mathrm{f}_{\mathrm{He}}$ from $3.2 \%$ (the reference case) to $1.6 \%$ 
increases $\mathrm{Q}_{\max }$ to 20 at $\mathrm{H}_{\mathrm{H} 98(\mathrm{y}, 2)}=1$ and the margin in $\mathrm{H}_{\mathrm{H} 98(\mathrm{y}, 2)}$ for achieving $\mathrm{Q}_{\max }=10$ to approximately 0.1 . These data are based on the premise that $\mathrm{P}_{\text {sep }}$ should be at least $45 \mathrm{MW}$ to remain in the ELMy H-mode [2].

\section{Dimensionless Scaling Approach}

The dimensionless scaling approach is based on the Kadomtsev's principle suggesting that confinement scalings can be expressed in a non-dimensional form as [1]

$\mathrm{B} \tau_{\mathrm{E}}=\left(\rho^{*}\right)^{-\left(2+\alpha_{\rho}\right)} \mathrm{F}\left(\beta, v^{*}, \mathrm{q}, \mathrm{R} / \mathrm{a}, \kappa, \delta, \ldots\right)$,

where $\alpha_{\rho}=0$ and 1 correspond to Bohm and gyroBohm scaling, respectively. Parameter $\alpha$ was measured in a number of tokamaks and found to be close to 1 in low-q ( 3-4) ELMy H-mode discharges. In particular, $\alpha_{\rho} \approx 1.15$ was obtained in DIII-D [12] and $\alpha_{\rho} \approx 0.7$ in JET [13]. Note that the latter value coincides with that in the dimensionless form of scaling (1). Eq. (3) permits the scaling of the product $\mathrm{B} \tau_{\mathrm{E}}$ from present day machines to larger devices by decreasing $\rho *$ while keeping other non-dimensional parameters fixed. The values of $\mathrm{B} \tau_{\mathrm{E}}$ extrapolated to ITER from JET pulse \#42983 [14] (by a factor of 2.25 in $\rho *$ ) are 25.1 at $\alpha_{\rho}=1.15$ and 17.4 at $\alpha_{\rho}=$ 0.7 . Extrapolated values of $\mathrm{W}_{\text {th }}$ (thermal plasma energy) and $\mathrm{P}_{\text {fus }}$ are $293 \mathrm{MJ}$ and $335 \mathrm{MW}$ resulting in Q of 13 and 6 for $\alpha_{\rho}$ of 1.15 and 0.7 , respectively. Although this pulse looks as a relevant one, a number of its dimensionless parameters, i.e., $\delta=0.23, \beta_{\mathrm{N}, \text { th }}=1.46$ and presumably the toroidal Mach number deviate significantly from ITER. Therefore, discharges with a better match to the dimensionless ITER parameters are needed to improve the accuracy of this method. According to the similarity scaling experiments, the dependence of $\mathrm{B} \tau_{\mathrm{E}}$ on $\beta$ is very weak, i.e., $\mathrm{B} \tau_{\mathrm{E}} \propto \beta^{0.03}$ in DIII-D [12] and $\mathrm{B} \tau_{\mathrm{E}} \propto \beta^{-0.05}$ in JET [13], in a clear contradiction to the dimensionless form of the global confinement scaling. The origin of this discrepancy is not yet understood.

\section{Theory-Based Model Predictions}

In this section, the values of $\mathrm{Q}$ and $\mathrm{P}_{\text {fus }}$ predicted for ITER by three theory-based transport models, i.e., Multi-Mode (MMM) [15], Weiland [16] and IFS/PPPL [17], are compared. All three models utilise transport driven by the drift wave turbulence although detailed treatment of the physics of microinstabilities is somewhat different. The IFS/PPPL model and the related, more complete GLF23 model [18], are based on non-linear gyro-fluid turbulence simulations for the amplitude of the ITG (ion-temperature-gradient) mode together with linear gyro-kinetic computations for the threshold of this mode. Transport obtained in this way is higher than that predicted by the more advanced non-linear gyro-kinetic turbulence simulations [19], and GLF23 tends to underpredict experimental thermal energy at higher edge temperatures for ASDEX Upgrade [20]. The Weiland reactive drift model, which provides the ITG/TEM (trapped electron mode) part of MMM, comes close to agreeing with the results of the non-linear gyrokinetic simulations [19]. In addition, electromagnetic effects in the Weiland model have been developed to treat finite beta effects. The MMM model also includes transport due to resistive and kinetic ballooning modes and neoclassical transport. Fig. 3 shows the values of Q versus $\mathrm{T}_{\text {ped }}$ predicted for ITER by the Weiland [21] and MM models $\left(\mathrm{T}_{\text {ped }}\right.$ is the ion temperature at the top of the edge pedestal). According to these simulations ITER will need $\mathrm{T}_{\text {ped }}=2.3-3.9 \mathrm{keV}$ to obtain $\mathrm{Q}=10$ at $\mathrm{I}=15 \mathrm{MA}$ and $\mathrm{P}_{\mathrm{aux}}=40 \mathrm{MW}$. The horizontal bars at the bottom of the figure show approximate ranges of $\mathrm{T}_{\text {ped }}$ predicted for ITER by different pedestal scalings [7, 10, 22, 23 ] assuming $\mathrm{n}_{\text {ped }}=0.7<\mathrm{n}>[7]$. One can see that the scatter in predicted $\mathrm{T}_{\text {ped }}$ is very large.

To evaluate the uncertainties in the theory-based model predictions for ITER we run the models at the same input parameters using the 1.5D transport code ASTRA [4]. The following simplified approach [24] was employed in the simulations. In the transport models, only diagonal terms of the turbulent transport matrix were retained. Heat diffusivities for electrons and ions were taken directly from the transport models while the particle flux was taken as 


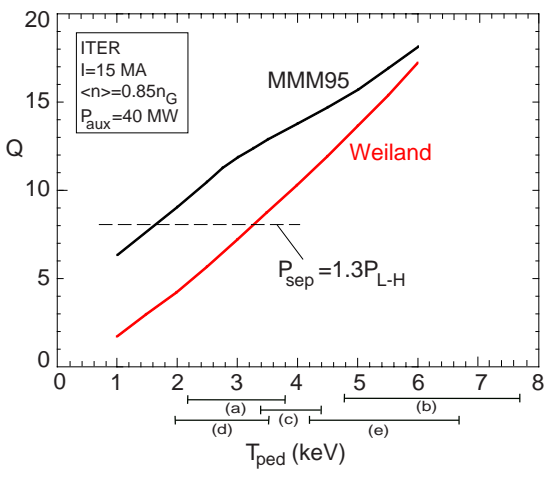

FIG.3. $Q$ versus $T_{\text {ped }}$ given by the $M M$ and Weiland models. Dashed line shows value of $Q$ compatible with $P_{\text {sep }}=1.3 x P_{L-H}$. The horizontal bars at the bottom show the ranges of $T_{\text {ped }}$ predicted by edge pedestal models (a) and (b) [10], (c) [7], (d) [22], and (e) [23].

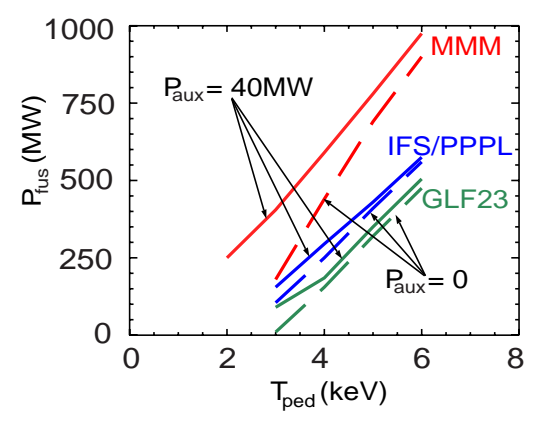

FIG. 4. $P_{\text {fus }}$ versus $T_{\text {ped }}$ predicted for ITER by the 'reduced' $M M$, IFS/PPPL and GLF23 models incorporated into the ASTRA code [24]. $I=15 \mathrm{MA}, \mathrm{n}_{e}>/ n_{G}$ $=0.85, P_{a u x}=40 \mathrm{MW}$ (solid curves) and $P_{a u x}=0$ (dashed curves). $f_{D T}=0.94$ was fixed in these simulations.

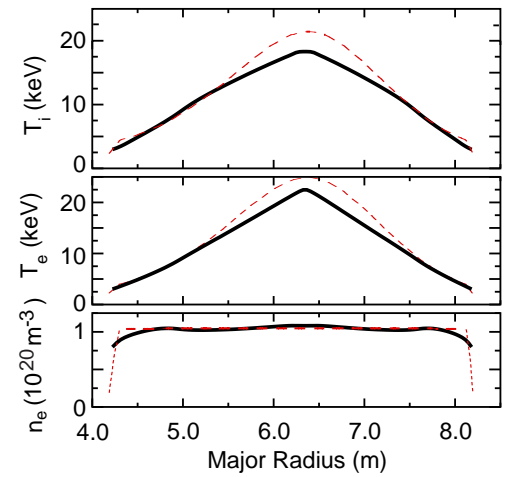

FIG. 5. Radial profiles of $T_{i}, T_{e}$ and $n_{e}$ predicted by MultiMode model at $T_{p e d}=2.74 \mathrm{keV}$ (solid curves) and by the model based on the empirical scaling (1) (dashed curves) for ITER with $I=15 M A,<n_{e}>/ n_{G}=$ 0.84 and $P_{a u x}=40 \mathrm{MW}$.

$\Gamma=v^{\text {neo }} n_{e}-\left(D_{e}{ }^{\text {neo }}+D_{e}{ }^{\text {an }}\right) \nabla n_{e}$ with $D_{e}{ }^{\text {neo }}$ and $v^{\text {neo }}$ being the neoclassical diffusion coefficient and the pinch velocity, respectively. The anomalous diffusion coefficient is taken as $\mathrm{D}_{\mathrm{e}}{ }^{\text {an }}=$ $0.2\left(\chi_{\mathrm{e}}{ }^{\mathrm{an}}+\chi_{\mathrm{i}}{ }^{\mathrm{an}}\right)$.Fig. 4 compares the ITER fusion powers predicted by ASTRA simulations using the 'reduced' Multi-Mode, IFS/PPPL and GLF23 models. One can see that the IFS/PPPL and GLF23 models predict significantly lower $P_{\text {fus }}$ at given $T_{\text {ped }}$ and require higher $T_{\text {ped }}$ for obtaining $\mathrm{Q}=10$ compared to the Multi-Mode model. $\mathrm{P}_{\text {fus }}$ increases with $\mathrm{T}_{\text {ped }}$ as $\mathrm{P}_{\text {fus }} \propto\left(\mathrm{T}_{\text {ped }}\right)^{\gamma}$ with $\gamma$ $\approx 1.25$ and $\approx 2$ for Multi-Mode and IFS/PPPL models, respectively. All these models predict a possibility of reaching ignition in ITER, i.e. plasma sustained by $\alpha$-particle heating only $\left(\mathrm{P}_{\mathrm{aux}}=\right.$ 0 ) at sufficiently high $\mathrm{T}_{\text {ped }} \geq 4.5-6 \mathrm{keV}$ (dashed curves in Fig. 4).

Fig. 5 shows $\mathrm{T}_{\mathrm{i}}, \mathrm{T}_{\mathrm{e}}$ and $\mathrm{n}_{\mathrm{e}}$ profiles in ITER at $\mathrm{Q} \approx 10$ predicted by the original Multi-Mode model with $\mathrm{T}_{\text {ped }}(\mathrm{r} / \mathrm{a}=1.0)=2.74 \mathrm{keV}$, i.e., $\mathrm{T}_{\text {ped }}(\mathrm{r} / \mathrm{a}=0.95)=3.6 \mathrm{keV}$, given by the pedestal model based on magnetic and flow shear stabilisation (solid curves) [7]. Also shown are plasma profiles obtained in ASTRA simulations using the scaling (1) [25] (dashed curves). The same major input parameters, $\mathrm{I}=15 \mathrm{MA},\left\langle\mathrm{n}_{\mathrm{e}}>/ \mathrm{n}_{\mathrm{G}} \approx 0.85\right.$ and $\mathrm{P}_{\mathrm{aux}}=40 \mathrm{MW}$, and the averaged impurity concentration of $2 \% \mathrm{Be}$ and $0.12 \%$ Ar were used in both simulations. The central value of $Z_{\text {eff }}(\approx 1.44)$ in MMM case was $19 \%$ smaller compared to simulations with scaling (1) resulting in higher central DT ion fraction. This explains the similar fusion powers (423 and 410 MW) obtained in these simulations although the central ion temperature obtained in MMM simulation is smaller.

Fig. 6 shows $\mathrm{Q}$ versus $<\mathrm{n}_{\mathrm{e}}>/ \mathrm{n}_{\mathrm{G}}$ for three cases assuming $\mathrm{n}_{\text {ped }}=0.7<\mathrm{n}_{\mathrm{e}}>$. The original ('full') MMM [7] and 'reduced' MMM [24] results are obtained using two different pedestal models described in Ref. [7] and Ref. [10], respectively. Both curves demonstrate a similar, relatively weak dependence of $\mathrm{Q}$ on plasma density in the $<\mathrm{n}_{\mathrm{e}}>/ \mathrm{n}_{\mathrm{G}}$ range of $0.6-1$, although with $\mathrm{Q}$ values diverging by a factor of 2 . The dependence of $\mathrm{Q}$ on $<\mathrm{n}_{\mathrm{e}}>/ \mathrm{n}_{\mathrm{G}}$ based on the ITERH$98 \mathrm{P}(\mathrm{y}, 2)$ scaling is stronger, and $\mathrm{Q}$ values at $<\mathrm{n}_{\mathrm{e}}>/ \mathrm{n}_{\mathrm{G}}$ ratio of $0.7-0.9$ are close to those given by the full MMM. All available scalings for the edge pedestal show increase in $T_{\text {ped }}$ with the plasma current, $T_{\text {ped }}$ $\propto I^{\gamma}$ with $\gamma$ in the range of $0.6[23]$ to $2[7,22]$.

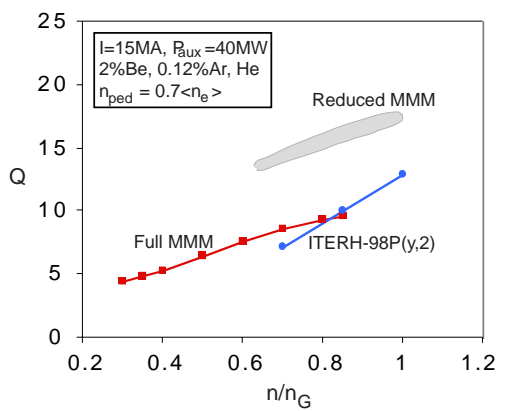

FIG. 6. $Q$ versus $<n_{e}>/ n_{G}$ predicted for ITER by the original and 'reduced' Multi-Mode models with two different scalings for $T_{\text {ped }}$. Also shown is $Q$ dependence on $<n_{e}>/ n_{G}$ based on ITERH-98P $(y, 2)$ confinement scaling. 
A scan with the plasma current at $\mathrm{T}_{\text {ped }}=$ const and $<\mathrm{n}_{\mathrm{e}}>/ \mathrm{n}_{\mathrm{G}}=$ const gives $\mathrm{Q} \propto \mathrm{I}^{\xi \mathrm{I}}$ with $\xi_{\mathrm{I}}=2.3$ for the Multi-Mode model that is turned to $\xi_{\mathrm{I}}=3.0-4.8$ taking account of the above $\mathrm{T}_{\text {ped }}$ scalings with I. Note that $\xi_{\mathrm{I}}=3.4$ given by the scaling (1) is within this range.

\section{Summary}

The possibility of achieving high Q $(\geq 10)$ in ITER predicted by the transport model based on the ITERH-98P $(\mathrm{y}, 2)$ confinement scaling is reasonably well confirmed by the dimensionless scaling analysis and theory-based transport modelling. Reduction of $\mathrm{He}$ concentration predicted by the B2/Eirene code, if realized, will significantly increase the operational window for $\mathrm{Q}=$ 10. Dimensionless scaling projection from the JET pulse \#42983 to the ITER reference inductive regime gives $\mathrm{Q}=6-13$ that is close to predictions based on the global confinement scaling. According to the Multi-Mode, Weiland and IFS/PPPL theory-based transport models, the pedestal temperature $T_{\text {ped }}$ at $\mathrm{r} / \mathrm{a}=0.95$ required for achieving $\mathrm{Q}=10$ in ITER is $3.6-5.5 \mathrm{keV}$. These values of $T_{\text {ped }}$ are within the presently large possibility range of $T_{\text {ped }}$ projections. A more accurate model of the edge pedestal and its self-consistent coupling to the core plasma are required. Further elaboration and testing of theory-based transport models is needed in order to select the most reliable one for the accurate prediction of ITER performance.

\section{References}

[1] ITER PHYSICS BASIS, Nucl. Fusion 39 (1999) 2175.

[2] KARDAUN, O., Nucl. Fusion 42 (2002) 841; KARDAUN, O.J.W.F., Report IPP-IR2002/5-1.1, Max-Planck-Institut für Plasmaphysik, Garching, http://www.ipp.mpg.de/ipp/netreports.

[3] ITER TECHNICAL BASIS, ITER EDA Documentation Series No. 24, Chapter 4, IAEA, Vienna, 2002.

[4] PEREVERZEV, G.V., YUSHMANOV, P.N., IPP Report 5/98, February 2002.

[5] SNIPES, J.A., et al., Plasma Phys. Control. Fusion 42 (2000) A299.

[6] CORDEY, J.G., et al., $28^{\text {th }}$ EPS Conf. on Contr. Fusion and Plasma Phys. Funchal, 18-22 June 2001, P3.11, ECA Vol. 25A (2001) 969.

[7] KRITZ, A.H., et al., $29^{\text {th }}$ EPS Conf. on Contr. Fusion and Plasma Phys. Montreux, 2002, ECA Vol. 26B (2002) D-5.001.

[8] LANG, P.T., et al., Nucl. Fusion 40 (2000) 245; POLEVOI, A.R., et al., this Conference, paper CT/P-08.

[9] TAKIZUKA, T., Plasma Phys. Control. Fusion 40 (1998) 851.

[10] CORDEY, J.G., et al., this Conference, paper CT/P-02.

[11] KUKUSHKIN, A., et al., Plasma Phys. Control. Fusion 44 (2002) 931.

[12] PETTY, C.C., et al., Nucl. Fusion 38 (1998) 1183; PETTI, C.C., et al., Phys. Plasmas 5 (1998) 1695.

[13] JET Team (presented by J.G. Cordey), in Fusion Energy 1996 (Proc. $16^{\text {th }}$ Int. Conf. Montreal, 1996) Vol.1, IAEA, Vienna (1997) 603.

[14] HORTON, L.D., SARTORI, P., BALET, B., et al., Nucl. Fusion 39 (1999) 993.

[15] BATEMAN, G., KRITZ, A.H., KINSEY, J.E., et al., Phys. Plasmas 5 (1998) 1793.

[16] NORDMAN, H., et.al., Nucl Fusion 39 (1999) 1157.

[17] KOTSCHENREUTHER, M., DORLAND, W., et al., Phys. Plasmas 2 (1995) 2381.

[18] WALTZ, R.E., STAEBLER, G.M., et al., Phys. Plasmas 4 (1997) 2482.

[19] DIMITS, A.M., et al., Phys. Plasmas 7 (2000) 969.

[20] TARDINI, G., et al., Nucl. Fusion 42 (2002) 258.

[21] WEILAND, J., $28^{\text {th }}$ EPS Conf. on Contr. Fusion and Plasma Phys. Funchal, 18-22 June 2001, P-2.039.

[22] SUGIHARA, M., et al., Nucl. Fusion 40 (2000) 1743.

[23] SUGIHARA, M., et al., $57^{\text {th }}$ Annual Meeting of the Phys. Soc. Japan (2002).

[24] PEREVERZEV, G.V., et al., $29^{\text {th }}$ EPS Conf. on Contr. Fusion and Plasma Phys. Montreux, 2002, ECA Vol. 26B (2002) P-1.072.

[25] POLEVOI, A.R., et al., J. Plasma Fusion Res. SERIES Vol. 5 (2002), to be published. 